\title{
Family characteristics and health-related behaviours influence physical fighting involvement in late adolescence: a study from 13 to 17 years of age
}

\author{
Sílvia Fraga $^{1}$ - Elisabete Ramos ${ }^{1,2} \cdot$ Henrique Barros ${ }^{1,2}$
}

Received: 19 January 2016 / Accepted: 10 May 2016 /Published online: 26 May 2016

(C) Springer-Verlag Berlin Heidelberg 2016

\begin{abstract}
Aim We aimed to assess the contribution of early characteristics in adolescence as associated factors of later involvement in physical fighting.

Subject and methods Based on data from a cohort of adolescents, we evaluated 1,687 participants, recruited in public and private schools in Porto, Portugal. Information on social and behavioural characteristics was collected using the same selfadministered questions at 13 and 17 years of age. Logistic regression was used to estimate the magnitude of associations. Results In both genders, physical fighting was significantly associated with living in a sole parent family, in particular only with the mother, and with early grade retention. Also, early cigarette smoking and alcohol drinking initiation were significantly associated with later involvement in fights.

Conclusion Our results show that family characteristics and modifiable behavioural trajectories are important determinants of later involvement in physical fighting.
\end{abstract}

Keywords Physical fighting $\cdot$ Adolescence $\cdot$ Health behaviours $\cdot$ Cohort study

Sílvia Fraga

silfraga@med.up.pt

1 EPIUnit-Institute of Public Health, University of Porto, Rua das Taipas 135, 4050-600 Porto, Portugal

2 Department of Clinical Epidemiology, Predictive Medicine and Public Health, University of Porto Medical School, Porto, Portugal

\section{Introduction}

Physical fighting is a common form of interpersonal violence among adolescents (Muula et al. 2008; Pickett et al. 2005) that typically involves two or more adolescents who have chosen to use physical force to solve a conflict or argument. This violent behaviour is characterized by an imbalance of power, whereby those involved are simultaneously victims and perpetrators. In Europe, the average rate of involvement in physical fighting among adolescents was estimated as $58 \%$ in boys and $24 \%$ in girls, with a wide country variation (Pickett et al. 2005).

Physical fighting is usually taken as a normal part of growing up; however, it can be a serious problem among older adolescents because it tends to be associated with other critical behaviours in adolescence (Bartlett et al. 2005; Fraga et al. 2011; Melzer-Lange 1998; Smith-Khuri et al. 2004). Adolescents who engage in fights more frequently tend to report the use of illegal drugs and alcohol drinking (Howard et al. 2007, 2008; Rudatsikira et al. 2008b) and carrying weapons (Malek et al. 1998; Muula et al. 2008).

Although recent data showed a decline in adolescent physical fighting (Pickett et al. 2012), this behaviour still requires surveillance and special attention for specific groups of adolescents, in particular boys and those who engaged in multiple risk-taking.

Early adolescence is characterized by the transition from elementary to middle school and is also a time of participation in risk and additive behaviours. Tobacco and alcohol are among the first substances consumed by adolescents, and are often referred to as gateway drugs (Kirby and Barry 2012). Early adolescent drugs use has been shown to be associated with later substance abuse, school failure and juvenile offending (Fergusson and Horwood 1997); however, all these adverse effects of transition may be mediated by the family 
context. Although the influence of peers increases in this stage, it is recognized that an initial foundation of good family functioning is associated with lower levels of aggression and other externalizing problems (Heidgerken et al. 2004; Kramer-Kuhn and Farrell 2016). Adolescents from unstructured families, namely single-parent homes are more likely to engage in delinquent behaviours (Breivik et al. 2009), while those adolescents that perceived parental support at early adolescence seem to present lower levels of aggression later (Kramer-Kuhn and Farrell 2016).

The possibility to use a population-based cohort that allows for the monitoring of participants from the very early to the later stage of adolescence contributes to a better understanding of the risk and protective factors that predict the engagement in aggressive behaviours. Thus, by prospectively studying a cohort of adolescents, we intended to assess the contribution of family characteristics and the initiation of behaviours in adolescence as associated factors of involvement in physical fighting.

\section{Methods}

\section{Study and participants}

The present study is based on information collected from 1 , 687 adolescents recruited in 2003 and followed in 2007 as part of the EPITeen cohort. The general study procedures have been described in detail elsewhere (Araujo et al. 2012; Ramos and Barros 2007). In brief, during the 2003/2004 academic year, the research team approached all public and private schools in Porto, Portugal, that provided teaching to adolescents born in 1990. Schools were asked to participate by putting researchers in contact with students and their parents or legal guardians.

Parents and adolescents individually received written information describing the study purpose and its design. Additionally, the study was presented at each school during special meetings arranged according to parents or guardians' convenience. We identified 2,787 eligible students of whom $77.5 \%$ agreed to participate and provide information for at least part of the evaluation protocol (Ramos and Barros 2007).

The first follow-up evaluation of this cohort was conducted during 2007/2008. Re-evaluations were scheduled through the schools or directly with the participants. The follow-up evaluation was conducted using the baseline protocol. Of the 2,160 initial participants, 1,716 (79.4\%) accepted to participate in the second wave (17 years old). In the present analysis, we considered 1,687 participants with complete information on physical fighting involvement. Written informed consent was obtained from all participants and their parents or legal guardians at each study wave.

\section{Procedures and data collection}

Information on social and behavioural characteristics was collected using self-administered questionnaires (one completed at home, another at school) at both 13 and 17 years of age. Physical fighting was only assessed at 17 years of age, according to the following question: "During the past 12 months, how many times were you involved in a physical fight?" Closed option answers ranged from never to 12 times or more. For the analysis, physical fighting was computed as yes or no.

We characterized the family context, corresponding to divorces or separations and resulting in the adolescent living with only one of the parents (almost always the mother), by using the baseline information (13 years of age) because these characteristics only changed for 51 adolescents (4\%) through the age of 17. Parents' educational level was measured as the number of successfully completed years of formal schooling. In the analysis we classified adolescents based on the parent with the highest educational level. Parent-child cohabitation was assessed during the cohort recruitment and adolescents were classified as one of the following: living with both parents, in sole parent families (father or mother) or with neither parent.

A similar questionnaire was administered at the ages of 13 and 17 and information was then combined to characterize the adolescent's behaviour. The type of school was classified by the adolescent's school track as always public ( public $_{13}$ years public $_{17}$ years $)$, private or moving to private (private/ public $_{13}$ years - private $_{17 \text { years }}$ ), moving from private to public (private 13 years - public $_{17}$ years) or out of school (e.g. vocational training course, dropping out of school). Grade retention was considered when the student remained at that same level for the subsequent school year. School grade retention was assessed at both evaluations and adolescents were classified as never having grade retention $\left(\mathrm{no}_{13}\right.$ years $-\mathrm{no}_{17}$ years $)$ or if ever retained, classified as grade retention after 13 years old $\left(\mathrm{no}_{13}\right.$ years $-\mathrm{yes}_{17}$ years $)$ or before 13 years old ( $\mathrm{yes}_{13}$ years yes 17 years).

Sport practice was assessed at 13 and 17 years of age using the question "Apart from school activities, how frequently do you practice sports for at least 20 minutes?", but for analysis participants were grouped dichotomously as practicing in sports or not participating. Information of both study waves allowed for computing a variable that reported changing behaviour. Adolescents were asked to report the time spent watching television and playing on computer or video games during weekends separately and were classified dichotomously as watching $\mathrm{TV} /$ playing on computers for less $\left(\mathrm{no}_{13}\right.$ years $\mathrm{no}_{17 \text { years }}$ ) or more than $2 \mathrm{~h}$ ( yes $_{13 \text { years }}-$ yes $_{17 \text { years }}$ ) or as moving between categories $\left(\mathrm{no}_{13}\right.$ years $-\mathrm{yes}_{17}$ years $)$ or $\left(\mathrm{yes}_{13}\right.$ years $\mathrm{no}_{17 \text { years }}$.

Adolescents were classified as never smokers $\left(\mathrm{no}_{13}\right.$ years no $_{17 \text { years }}$ ) or, if they had experienced cigarette smoking, as 
one of two categories of ever smokers: (1) after 13 years if they did not smoke at 13 but smoked at 17 years of age $\left(\right.$ no $_{13}$ years - yes $_{17}$ years $)$; or (2) before 13 years, if they already reported smoking in the 13-year-old questionnaire (yes ${ }_{13}$ years - yes $_{17}$ years). The same procedure was followed regarding alcohol drinking (never drinker; starting after 13 or starting before 13 years old).

\section{Data analysis}

To estimate the magnitude of the associations between early behaviours and physical fighting, logistic regression was used - crude and adjusted odds ratios, with $95 \%$ confidence intervals (OR, $95 \% \mathrm{CI}$ ). All other covariates were individually checked using manual forward addition and backward deletion and kept on the final model if they changed the ORs for physical fighting involvement at least in $10 \%$. The final model was fitted stratified by gender. Statistical analysis was performed with SPSS 18.0 software and the level of significance was set at 0.05 .

\section{Results}

In our sample, $32.5 \%$ (19.3\% in girls and $47.0 \%$ in boys, $p<0.001$ ) of 17 -year-old adolescents were involved in physical fighting during the previous year. Of them, $47.9 \%$ (54.7\% in girls and $44.9 \%$ in boys) reported only one episode; $35.3 \%$ (30.0\% in girls and $37.7 \%$ in boys) two or three episodes; and $16.8 \%$ (15.3\% in girls and $17.4 \%$ in boys) four or more fighting episodes. Almost half of the episodes have occurred on school property.

As shown in Table 1, in the crude analysis considering female participants, physical fighting was significantly more frequent among those with less educated parents, with siblings or living with the mother in sole parent families or with neither parent. Girls that abandoned school, with a history of grade retention, of smoking or drinking alcohol, more often reported involvement in physical fighting. Similar results were observed in boys (Table 2), although differences were not statistically significant regarding parents' education, siblings and school type.

In girls, and after adjustment for parent-child cohabitation, parents' education and cigarette smoking, physical fighting involvement was significantly associated with living only with the mother $(\mathrm{OR}=1.64,95 \% \mathrm{CI} 1.04-2.57)$, and having experienced grade retention either after $(\mathrm{OR}=2.26,95 \% \mathrm{CI}$ $1.37-3.72)$ or before 13 years of age $(\mathrm{OR}=2.61,95 \% \mathrm{CI}$ $1.54-4.42)$. On the other hand, more educated parents resulted in a protective effect $(\mathrm{OR}=0.51,95 \% \mathrm{CI} 0.30-0.87$, if parental education was between 9 and 12 years and $\mathrm{OR}=0.47$, $95 \%$ CI $0.27-0.79$ for those with parental education higher than 12 years). Girls who always practiced sports had twice the odds of being engaged in fights $(\mathrm{OR}=2.20,95 \% \mathrm{CI} 1.13$
4.26). Cigarette smoking and alcohol drinking were significantly associated with physical fighting. In girls who reported physical fighting, the earlier they started smoking the stronger the association was with involvement in physical fighting but no such trend was found for drinking.

In boys, and after adjustment for the same set of variables, physical fighting involvement was significantly associated with living only with the mother $(\mathrm{OR}=1.75,95 \% \mathrm{CI} 1.15$ 2.66) and early school grade retention $(\mathrm{OR}=2.34,95 \% \mathrm{CI}$ 1.49-3.67). Boys who kept playing $(\mathrm{OR}=1.55,95 \% \mathrm{CI}$ 0.99-2.42) or started to play on computers more than $2 \mathrm{~h}$ showed increased odds $(\mathrm{OR}=1.74,95 \% \mathrm{CI} 1.08-2.82)$ of involvement in fights. Cigarette smoking and early initiation of drinking $(\mathrm{OR}=1.75,95 \% \mathrm{CI} 1.03-2.99)$ were significantly associated to fighting. Parents' education, school type, sport activities and amount of time watching TV were not associated with involvement in fighting among boys.

\section{Discussion}

In our study we found that almost half of boys and a third of girls aged 17 have dealt with a conflict through the involvement in a physical fight. Once these adolescents are close to reaching the age of the majority, these figures are even more worrying. The overall prevalence of physical fighting in the current study was quite similar to the prevalence found in other studies (Djerboua et al. 2016; Pickett et al. 2005). However, in a large number of countries, the frequency of physical fighting has declined among adolescents over time during the past decade, as evidenced by multiple crosssectional surveys (Pickett et al. 2012).

Additionally, our prospective analysis showed an independent association with family characteristics, poor school achievement and early engagement in typical unhealthy behaviours. Tracking the adolescent period allowed for understanding the contribution of experimentation with substances, life styles and family context at the beginning of this stage of life to the involvement of physical fighting near adulthood.

It has been argued that across childhood and adolescence, risks tend to cluster in two patterns: the early accumulated risk cluster and the adolescent-onset risk cluster (Catalano et al. 2012). The first one is related to risks that accumulate early in the life course, when developmental challenges are not met and problems begin to cascade, such as early family adversity or exposure to abuse and neglect, making it harder for children to be ready for school and hindering their academic achievement. The other pattern arises in adolescence and can affect even those adolescents without accumulated early risk. This pattern postulates that in the absence of protective reinforcements, adolescents' behaviours can be particularly susceptible to the negative influence of peers. Youth violence cannot be explained without taking into consideration the significance of structural and 
Table 1 Association of family characteristics and adolescents' behaviours between 13 and 17 years old with involvement in fights at 17 years old (among girls)

\begin{tabular}{|c|c|c|c|c|c|}
\hline & \multicolumn{5}{|c|}{ Physical fighting } \\
\hline & $\begin{array}{l}\text { No } \\
n(\%)\end{array}$ & $\begin{array}{l}\text { Yes } \\
n(\%)\end{array}$ & $p$-value & $\begin{array}{l}\text { Crude OR } \\
(95 \% \text { CI })\end{array}$ & $\begin{array}{l}\text { Adjusted OR } \\
(95 \% \text { CI })\end{array}$ \\
\hline \multicolumn{6}{|l|}{ Parent-child cohabitation 13 years } \\
\hline Father and mother & $551(82.9)$ & $106(17.1)$ & 0.014 & 1 & 1 \\
\hline Only mother & $122(73.1)$ & $45(26.9)$ & & $1.79(1.20-2.67)$ & $1.64(1.04-2.57)$ \\
\hline Only father & $26(86.7)$ & $4(13.3)$ & & $0.75(0.26-2.19)$ & $0.83(0.27-2.54)$ \\
\hline No parents & $23(71.9)$ & $9(28.1)$ & & $1.90(0.86-4.22)$ & $1.35(0.53-3.43)$ \\
\hline \multicolumn{6}{|l|}{ Siblings $_{13}$ years } \\
\hline No & $156(86.7)$ & $24(13.3)$ & 0.029 & 1 & 1 \\
\hline Yes & $552(79.1)$ & $146(20.9)$ & & $1.72(1.08-2.74)$ & $1.71(0.98-2.97)$ \\
\hline \multicolumn{6}{|l|}{ Parents' education (years) 13 years } \\
\hline$<6$ & $177(74.7)$ & $60(25.3)$ & $<0.001$ & 1 & 1 \\
\hline $7-9$ & $129(73.7)$ & $46(26.3)$ & & $1.05(0.67-1.64)$ & $1.04(0.63-1.73)$ \\
\hline $10-12$ & $198(85.7)$ & $33(14.3)$ & & $0.49(0.31-0.79)$ & $0.51(0.30-0.87)$ \\
\hline$>12$ & $202(87.1)$ & $30(12.9)$ & & $0.44(0.27-0.71)$ & $0.47(0.27-0.79)$ \\
\hline \multicolumn{6}{|l|}{ School type } \\
\hline Public $_{13}$ years - public $_{17 \text { years }}$ & $454(79.4)$ & $118(20.6)$ & 0.010 & 1 & 1 \\
\hline Private/public $_{13}$ years - private $_{17}$ years & $86(81.1)$ & $20(18.9)$ & & $0.89(0.53-1.52)$ & $1.23(0.67-2.26)$ \\
\hline Private $_{13 \text { years }}-$ public $_{17 \text { years }}$ & $120(90.9)$ & $12(9.1)$ & & $0.38(0.21-0.72)$ & $0.58(0.29-1.19)$ \\
\hline Left school $_{17 \text { years }}$ & $45(73.8)$ & $16(26.2)$ & & $1.37(0.75-2.51)$ & $1.24(0.62-2.49)$ \\
\hline \multicolumn{6}{|l|}{ Grade retention } \\
\hline $\mathrm{No}_{13}$ years $-\mathrm{no}_{17}$ years & $469(87.5)$ & $67(12.5)$ & $<0.001$ & 1 & 1 \\
\hline $\mathrm{No}_{13}$ years - yes $_{17 \text { years }}$ & $112(71.8)$ & $44(28.2)$ & & $2.75(1.78-4.24)$ & $2.26(1.37-3.72)$ \\
\hline Yes $_{13}$ years - yes $_{17 \text { years }}$ & $117(66.5)$ & $59(33.5)$ & & $3.53(2.36-5.29)$ & $2.61(1.54-4.42)$ \\
\hline \multicolumn{6}{|l|}{ Sport activities } \\
\hline $\mathrm{No}_{13}$ years - no 17 years & $95(86.4)$ & $15(13.6)$ & 0.089 & 1 & 1 \\
\hline Yes $_{13}$ years - no 17 years & $123(84.8)$ & $22(15.2)$ & & $1.13(0.56-2.30)$ & $1.23(0.57-2.66)$ \\
\hline $\mathrm{No}_{13}$ years - yes 17 years & $94(86.2)$ & $15(13.8)$ & & $1.01(0.47-2.18)$ & $1.13(0.48-2.65)$ \\
\hline Yes $_{13}$ years - yes 17 years & $346(78.8)$ & $93(21.2)$ & & $1.70(0.94-3.07)$ & $2.20(1.13-4.26)$ \\
\hline \multicolumn{6}{|l|}{ Cigarette smoking } \\
\hline $\mathrm{No}_{13}$ years $-\mathrm{no}_{17}$ years & $366(87.1)$ & $54(12.9)$ & $<0.001$ & 1 & 1 \\
\hline $\mathrm{No}_{13}$ years - yes $_{17 \text { years }}$ & $150(77.3)$ & $44(22.7)$ & & $1.99(1.28-3.09)$ & $1.88(1.19-2.98)$ \\
\hline Yes $_{13 \text { years }}-$ yes $_{17 \text { years }}$ & $135(20.7)$ & $46(25.4)$ & & $2.31(1.49-3.59)$ & $2.39(1.51-3.78)$ \\
\hline \multicolumn{6}{|l|}{ Alcohol drinking } \\
\hline $\mathrm{No}_{13}$ years $-\mathrm{no}_{17}$ years & $100(92.6)$ & $8(7.4)$ & 0.003 & 1 & 1 \\
\hline $\mathrm{No}_{13}$ years - yes $_{17 \text { years }}$ & $196(77.8)$ & $56(22.2)$ & & $3.57(1.64-7.78)$ & $4.45(1.80-10.99)$ \\
\hline Yes $_{13}$ years - yes $_{17}$ years & 347 (79.6) & $89(20.4)$ & & $3.21(1.50-6.83)$ & $3.98(1.62-9.78)$ \\
\hline
\end{tabular}

a Adjustment for parent-child cohabitation, parents' education and cigarette smoking

Italicized data refer to statistically significant results

contextual factors (Zahn et al. 2004) and therefore if we understood the adolescence experience, it would add an important contribution in explaining physical fighting involvement.

Also, we should keep in mind the co-occurrence of unhealthy factors which appears to develop during the critical transition period into early adolescence, and, as our study strengthens, early engagement in unhealthy behaviours should be monitored to better identify adolescents at risk of being involved in violent behaviour.

The family context was significantly associated to physical fighting involvement late in adolescence; and, once these characteristics (parents' education, presence of siblings and household type) remained unchanged through the observation period, it favours a stable early influence. It has been shown 
Table 2 Association of family characteristics and adolescents' behaviours between 13 and 17 years old with involvement in fights at 17 years old (among boys)

\begin{tabular}{|c|c|c|c|c|c|}
\hline & \multicolumn{5}{|c|}{ Physical fighting } \\
\hline & $\begin{array}{l}\text { No } \\
n(\%)\end{array}$ & $\begin{array}{l}\text { Yes } \\
n(\%)\end{array}$ & $p$-value & $\begin{array}{l}\text { Crude OR } \\
(95 \% \mathrm{CI})\end{array}$ & $\begin{array}{l}\text { Adjusted OR }{ }^{\mathrm{a}} \\
(95 \% \mathrm{CI})\end{array}$ \\
\hline \multicolumn{6}{|l|}{ Parent-child cohabitation 13 years } \\
\hline Father and mother & $339(56.5)$ & $261(43.5)$ & 0.010 & 1 & 1 \\
\hline Only mother & $58(42.3)$ & $79(57.7)$ & & $1.77(1.21-2.57)$ & $1.75(1.15-2.66)$ \\
\hline Only father & $10(47.6)$ & $11(52.4)$ & & $1.43(0.60-3.41)$ & $0.92(0.33-2.58)$ \\
\hline No parents & $8(38.1)$ & $13(61.9)$ & & $2.11(0.86-5.17)$ & $1.94(0.67-5.60)$ \\
\hline \multicolumn{6}{|l|}{ Siblings $_{13}$ years } \\
\hline No & $83(52.2)$ & $76(47.8)$ & 0.893 & 1 & 1 \\
\hline Yes & $342(53.2)$ & $301(46.8)$ & & $0.96(0.68-1.36)$ & $0.91(0.60-1.39)$ \\
\hline \multicolumn{6}{|l|}{ Parents' education(years) 13 years } \\
\hline$<6$ & $93(50.0)$ & $93(50.0)$ & 0.568 & 1 & 1 \\
\hline $7-9$ & $80(51.3)$ & $76(48.7)$ & & $0.95(0.62-1.45)$ & $1.10(0.68-1.79)$ \\
\hline $10-12$ & $119(53.6)$ & $103(46.4)$ & & $0.87(0.59-1.28)$ & $1.00(0.64-1.56)$ \\
\hline$>12$ & $136(56.4)$ & $105(43.6)$ & & $0.77(0.53-1.13)$ & $0.85(0.55-1.31)$ \\
\hline \multicolumn{6}{|l|}{ School type } \\
\hline Public $_{13}$ years - public 17 years & $280(51.3)$ & $266(48.7)$ & 0.247 & 1 & 1 \\
\hline 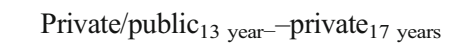 & $53(58.2)$ & $38(41.8)$ & & $0.75(0.48-1.18)$ & $0.84(0.51-1.39)$ \\
\hline Private $_{13 \text { years }}-$ public $_{17}$ years & $63(59.4)$ & $43(40.6)$ & & $0.72(0.47-1.10)$ & $0.67(0.40-1.10)$ \\
\hline Left school 17 years & $29(47.5)$ & $32(52.5)$ & & $1.16(0.68-1.97)$ & $0.73(0.39-1.36)$ \\
\hline \multicolumn{6}{|l|}{ Grade retention } \\
\hline $\mathrm{No}_{13}$ years - no $_{17 \text { years }}$ & $263(59.5)$ & $179(40.5)$ & $<0.001$ & 1 & 1 \\
\hline $\mathrm{No}_{13}$ years - yes $_{17}$ years & $78(50.6)$ & $76(49.4)$ & & $1.43(1.00-2.07)$ & $1.41(0.91-2.19)$ \\
\hline Yes $_{13 \text { years }}-$ yes $_{17 \text { years }}$ & $75(38.3)$ & $121(61.7)$ & & $2.37(1.68-3.35)$ & $2.34(1.49-3.67)$ \\
\hline \multicolumn{6}{|l|}{ Sport activities } \\
\hline No 13 years-no 17 years & $7(38.9)$ & $11(61.1)$ & 0.312 & 1 & 1 \\
\hline Yes $_{13 \text { years }}-$ no 17 years & $48(57.8)$ & $35(42.2)$ & & $0.46(0.16-1.32)$ & $0.77(0.24-2.43)$ \\
\hline $\mathrm{No}_{13}$ years - yes 17 years & $29(46.8)$ & $33(53.2)$ & & $0.72(0.25-2.11)$ & $0.91(0.28-2.97)$ \\
\hline Yes $_{13}$ years - yes 17 years & $313(54.7)$ & $259(45.3)$ & & $0.53(0.20-1.38)$ & $0.81(0.28-2.34)$ \\
\hline \multicolumn{6}{|l|}{ Cigarette smoking } \\
\hline $\mathrm{No}_{13}$ years $-\mathrm{no}_{17}$ years & $256(64.2)$ & $143(35.8)$ & $<0.001$ & 1 & 1 \\
\hline $\mathrm{No}_{13}$ years $-\mathrm{yes}_{17}$ years & $90(42.3)$ & $123(57.7)$ & & $2.45(1.74-3.44)$ & $2.48((1.75-3.52)$ \\
\hline Yes $_{13 \text { years }}-$ yes $_{17 \text { years }}$ & $38(36.5)$ & $66(63.5)$ & & $3.11(1.99-4.87)$ & $3.11(1.96-4.94)$ \\
\hline \multicolumn{6}{|l|}{ Alcohol drinking } \\
\hline $\mathrm{No}_{13}$ years $-\mathrm{no}_{17}$ years & $62(66.0)$ & $32(34.0)$ & 0.001 & 1 & 1 \\
\hline $\mathrm{No}_{13}$ years - yes $_{17 \text { years }}$ & $149(56.4)$ & 115 (43.6) & & $1.49(0.91-2.44)$ & $1.37(0.80-2.35)$ \\
\hline Yes $_{13}$ years - yes $_{17}$ years & $173(46.6)$ & $198(53.4)$ & & $2.22(1.38-3.56)$ & $1.75(1.03-2.99)$ \\
\hline
\end{tabular}

a Adjustment for parent-child cohabitation, parents' education and cigarette smoking

Italicized data refer to statistically significant results

that adolescents in non-partnered families are more prone to involvement in violent situations (Horta et al. 2010). We also found that those living only with the mother were at higher risk of involvement in physical fighting regardless of gender. However, we cannot exclude that the absence of additional significant associations when considering other types of family structures solely reflects lack of statistical power. Our findings support previous results showing that adolescents living only with their mothers were more likely to report fighting (Paschall et al. 1996), although this is not consistent with other studies that found a protective effect of living with the mother (Malek et al. 1998). In our study, we have a higher 
number of adolescents who are living with the mother-only compared to those adolescents who are living with the fatheronly, which limits the ability to better explore and understand this group. This low number is probably reflecting the Portuguese parental regulation, where usually the father has only the right of his children's custody in very specific circumstances. Families living only with the mother are likely to have fewer resources to allocate parenting and it has been associated with higher levels of stress. Therefore, a potential explanation relates to the mothers ability to deter violence when lacking economic sufficiency or the ability of offering guidance and discipline. Further, studies have shown that children of families in which the biological father resided in the household are less likely to be involved in violence (Berger et al. 2009). Also, if the mother was living with a man who was not the biological father, children seem to be significantly more likely to engage in violence than those who are living with the biological father (Berger et al. 2009). However, our study is limited in providing a comprehensive explanation because we did not collect information on the dynamics operating at the family structure such as the attachment to parents or contacts, and we did not assess if non-cohabitation was due to death of parents, or if there was a reconstituted family. Additionally, family and home may represent both a protective structure or a risky environment (Robinson et al. 2000), characterized by providing the experience of situations of violence, and the present study did not qualify the participants' shared family environment as violent or not. In the current analysis, we opted to characterize the early stage of adolescence by using the information collected at 13 years of age, once we believe that family functioning could have more influence in attitudes and behaviours at the earlier age. However, we have tested the results considering the $4 \%$ of the participants that have changed the family structure at the age of 17 but no significant changes were observed.

Parental education was not significantly associated with fighting in boys but showed a negative association with involvement in physical fighting in girls, probably reflecting that physical fighting is more generalized among boys, while girls from lower social class more frequently admit that behaviour. However, the overall results are in line with previous studies showing that individuals living in more socioeconomically disadvantaged environments are more prone to engage in physical fights (Tremblay et al. 1991).

By combining information of both study waves, describing different phases of adolescence, we were able to track the adolescent's history of health behaviours. No significant association was found between the type of school (privately owned or public) where education took place and physical fighting involvement but academic achievement was relevant. We interpreted poor school performance as an indicator of weak commitment or bonding to the academic environment (Saner and Ellickson 1996), and found a positive association in both genders between grade retention and fighting, showing that school early retention history is strongly associated with later violent behaviours.

The association between cigarette smoking, alcohol drinking and involvement in fight was previously reported in two cross-sectional surveys (Rudatsikira et al. 2008a, b). Additionally, a study of 4,187 adolescents aged 11-16 from 13 English schools also found an association between alcohol and victimization independent of their individual relation with physical aggression. It also provided evidence for the importance of reducing violence with a focus on preventing alcohol misuse, be it among victims or potential victims as among offenders (Shepherd et al. 2006). The National Longitudinal Study of Adolescent Health, a nationally representative school-based sample of 18,924 adolescents in grades 7-12 showed that $38 \%$ of adolescent drinkers reported fighting, including $12 \%$ who reported alcohol-related fighting (Swahn and Donovan 2006). Our study extended such findings in a prospective perspective showing that early exposure to cigarette smoking or alcohol is strongly associated with a later violent behaviour, though we could not isolate fighting as directly related to alcohol influence. Although experimentation with these substances may be considered normal in adolescence, we may note that this experimentation did not seem as innocuous as expected.

It was shown that adolescents' involvement in sports is associated with lower risk of attempted suicide and lower consumption of tobacco, wine and marijuana (Ferron et al. 1999). In our study, however, we did not find a significant association of fighting with sports among boys, but girls who practice sports during the whole period of 4 years seemed to be at higher risk for fighting. In Portugal, there is a low prevalence of sports practice among girls (Autran et al. 2012) and these girls were mostly athletes involved in high-level competitions, and it could be either the context for them to engage in fights or, one can speculate, sports practice promotes or responds to a competitive attitude that leads to violence. However, we do not have enough detailed information to further explore this association.

Watching TV and playing on computers are two sedentary behaviours that showed no significant association with physical fighting; however, we found a statistically significant association between playing computer games and physical fighting involvement among boys. In order to better understand these relations we would need information on TV contents, type of games, and parental monitoring or limiting practices.

\section{Limitations}

Our study did not enquire about exposures to interpersonal violence such as domestic violence or child abuse, which could be important modifiers of later individual behaviour. It should also be noted that no information on physical fighting 
was collected at 13 years of age. This may constitute an additional limitation of our study. One can speculate that individuals who were involved in fighting at 17 years of age had already been engaged in such or equivalent behaviours at 13 years of age. We used a physical fighting measurement that is a validated construct with extensive use in other adolescent health surveys (Pickett et al. 2005, 2012; Roberts et al. 2009). We could have opted to analyse a possible dose-response relation using categories representing the frequency of involvement in fights; however, besides the statistical power reduction, this approach as tested by Pickett et al. would increase the misclassification bias (Pickett et al. 2012). Thus, we found statistically significant and relevant associations when fighting was categorized as yes or no, and thus we are able to ensure the statistical power.

\section{Conclusion}

In summary, tracking the period of adolescence, it is observed that family characteristics and modifiable behavioural trajectories are important determinants of later involvement in physical fighting. Family adversity seems to be associated with higher levels of physical fighting engagement. Although experimentation with substances in early adolescence may be considered a normal behaviour, in this study this experience does not seem as innocuous as expected, which emphasizes the importance of being aware of individuals' behaviours at early adolescence.

Acknowledgements The study was supported by the Portuguese Foundation for Science and Technology (FCOMP-01-0124-FEDER021439, FCT PTDC/SAU-SAP/122904/2010). Sílvia Fraga is the recipient of a PostDoc grant from Fundação para a Ciência e a Tecnologia (SFRH/BPD/97015/2013). The EPIUnit, Institute of Public Health, University of Porto, Portugal (UID/DTP/04750/2013) is also funded by the Portuguese Foundation for Science and Technology.

\section{Compliance with ethical standards}

Ethical statement The study was approved by the Ethical Committee of Hospital S. João and University of Porto Medical School and the National Data Protection Commission.

Conflict of interest statement The authors declare that they have no conflict of interest.

\section{References}

Araujo J, Severo M, Ramos E (2012) Sleep duration and adiposity during adolescence. Pediatrics 130:e1146-e1154. doi:10.1542/peds.20111116

Autran RG, Ramos E, Pina Mde F, Santos MP (2012) The association between proximity to sports facilities and participation in sports among 13-year-olds in the city of Porto, Portugal. Cad Saude Publica 28:549-558
Bartlett R, Holditch-Davis D, Belyea M (2005) Clusters of problem behaviors in adolescents. Res Nurs Health 28:230-239. doi:10.1002/ nur.20078

Berger LM, Paxson C, Waldfogel J (2009) Mothers, men, and child protective services involvement. Child Maltreat 14:263-276. doi: $10.1177 / 1077559509337255$

Breivik K, Olweus D, Endresen I (2009) Does the quality of parent-child relationships mediate the increased risk for antisocial behavior and substance use among adolescents in single-mother and single-father families? J Divorce Remarriage 50:400-426

Catalano RF, Fagan AA, Gavin LE, Greenberg MT, Irwin CE Jr, Ross DA, Shek DT (2012) Worldwide application of prevention science in adolescent health. Lancet 379:1653-1664. doi:10.1016/s01406736(12)60238-4

Djerboua M, Chen BE, Davison CM (2016) Physical fighting, fightingrelated injuries and family affluence among Canadian youth. BMC Public Health 16:199. doi:10.1186/s12889-016-2886-3

Fergusson DM, Horwood LJ (1997) Early onset cannabis use and psychosocial adjustment in young adults. Addiction 92:279-296

Ferron C, Narring F, Cauderay M, Michaud PA (1999) Sport activity in adolescence: associations with health perceptions and experimental behaviours. Health Educ Res 14:225-233

Fraga S, Ramos E, Dias S, Barros H (2011) Physical fighting among school-going Portuguese adolescents: social and behavioural correlates. Prev Med 52:401-404. doi:10.1016/j.ypmed.2011.02.015

Heidgerken AD, Hughes JN, Cavell TA, Willson VL (2004) Direct and indirect effects of parenting and children's goals on child aggression. J Clin Child Adolescent Psychol 53(33):684-693. doi:10.1207/ s15374424jccp3304_4

Horta RL, Horta BL, Pinheiro RT, Krindges M (2010) Violent behavior in adolescents and parent-child cohabitation. Rev Saude Publica 44: 979-985

Howard DF, Wang MQ, Yan F (2007) Psychosocial factors associated with reports of physical dating violence among U.S. adolescent females. Adolescence 42:311-324

Howard DF, Wang MQ, Yan F (2008) Psychosocial factors associated with reports of physical dating violence victimization among U.S. adolescent males. Adolescence 43:449-460

Kirby T, Barry AE (2012) Alcohol as a gateway drug: a study of US 12th graders. J Sch Health 82:371-379. doi:10.1111/j.1746-1561.2012. 00712.x

Kramer-Kuhn AM, Farrell AD (2016) The promotive and protective effects of family factors in the context of peer and community risks for aggression. J Youth Adolesc. doi:10.1007/s10964-016-0438-x

Malek MK, Chang BH, Davis TC (1998) Fighting and weapon-carrying among seventh-grade students in Massachusetts and Louisiana. J Adolesc Health 2:94-102

Melzer-Lange MD (1998) Violence and associated high-risk health behavior in adolescents: substance abuse, sexually transmitted diseases, and pregnancy of adolescents. Pediatr Clin N Am 45:307-317

Muula AS, Rudatsikira E, Siziya S (2008) Correlates of weapon carrying among high school students in the United States. Ann General Psychiatry $7: 8$

Paschall MJ, Ennett ST, Flewelling RL (1996) Relationships among family characteristics and violent behavior by black and white male adolescents. J Youth Adolesc 25:177-197

Pickett W, Craig W, Harel Y, Cunningham J, Simpson K, Molcho M, Mazur J, Dostaler S, Overpeck MD, Currie CE, Group. HVaIW (2005) Cross-national study of fighting and weapon carrying as determinants of adolescent injury. Pediatrics 116:e855-e863

Pickett W, Molcho M, Elgar FJ, Brooks F, de Looze M, Rathmann K, Ter Bogt TF, Nic Gabhainn S, Sigmundova D, Gaspar de Matos M, Craig W, Walsh SD, Harel-Fisch Y, Currie C (2012) Trends and socioeconomic correlates of adolescent physical fighting in 30 countries. Pediatrics. doi:10.1542/peds.2012-1614 
Ramos E, Barros H (2007) Family and school determinants of overweight in 13-year-old Portuguese adolescents. Acta Paediatr 96:281-286

Roberts C, Freeman J, Samdal O, Schnohr CW, de Looze ME, Nic Gabhainn S, Iannotti R, Rasmussen M (2009) The Health Behaviour in School-aged Children (HBSC) study: methodological developments and current tensions. Int J Public Health 54(Suppl 2): 140-150. doi:10.1007/s00038-009-5405-9

Robinson J, Herot C, Haynes P, Mantz-Simmons L (2000) Children's story stem responses: a measure of program impact on developmental risks associated with dysfunctional parenting. Child Abuse Negl 24:99-110

Rudatsikira E, Muula AS, Siziya S (2008a) Prevalence and correlates of physical fighting among school-going adolescents in Santiago, Chile. Rev Bras Psiquiatr 30:197-202

Rudatsikira E, Muula AS, Siziya S (2008b) Variables associated with physical fighting among US high-school students. Clin Pract Epidemiol Ment Health 4:16

Saner H, Ellickson P (1996) Concurrent risk factors for adolescent violence. J Adolesc Health 19:94-103. doi:10.1016/1054-139x(96) 00131-0
Shepherd JP, Sutherland I, Newcombe RG (2006) Relations between alcohol, violence and victimization in adolescence. J Adolesc 29: 539-553. doi:10.1016/j.adolescence.2006.06.005

Smith-Khuri E, Iachan R, Scheidt PC, Overpeck MD, Gabhainn SN, Pickett W, Harel Y (2004) A cross-national study of violencerelated behaviors in adolescents. Arch Pediatr Adolesc Med 158: 539-544. doi:10.1001/archpedi.158.6.539

Swahn MH, Donovan JE (2006) Alcohol and violence: comparison of the psychosocial correlates of adolescent involvement in alcohol-related physical fighting versus other physical fighting. Addict Behav 31: 2014-2029. doi:10.1016/j.addbeh.2006.02.001

Tremblay RE, Loeber R, Gagnon C, Charlebois P, Larivee S, LeBlanc M (1991) Disruptive boys with stable and unstable high fighting behavior patterns during junior elementary school. J Abnorm Child Psychol 19:285-300

Zahn MA, Brownstein HH, Jackson SL (2004) Violence: from theory to research. LexisNexis, New York 